\title{
PODER Y DESHUMANIZACIÓN DEL SUJETO EN EL APANDO DE JOSÉ REVUELTAS
}

\author{
POR \\ ENEA ZARAMELLA \\ Princeton University
}

Las reflexiones que José Revueltas manifiesta mediante su producción literaria se articulan alrededor de la tensión política que dominaba la escena mexicana de los años sesenta. Sus escritos tuvieron gran resonancia sobre todo entre las generaciones más jóvenes ya que el valor mesiánico de su pensamiento -la promoción de cierto tipo de pureza con respecto al desarrollo del marxismo, según él, afectado por la deletérea contaminación del estalinismo- llamó particularmente la atención del movimiento estudiantil de 1968. La experiencia del escritor como prisionero político marcó, de manera tajante, su obra literaria y, desde su publicación en 1969, El Apando fue considerado por la crítica como una novela política que, a través de su narración dinámica, expresaba la necesidad de organizar un lenguaje literario que mediara entre las esferas del poder político y el pueblo. El objetivo de este diálogo parecía ser, directa o indirectamente, el de liberar a la población de la misma ansiedad que se halla en el texto: una forma de inquietud que en El Apando se expresa mediante la claustrofobia de la cárcel. Esto es, la cárcel implica el estatus de reclusión de la sociedad mexicana en un momento histórico caracterizado por la limitación de los derechos humanos en diferentes ámbitos de la vida cotidiana - notorio es el suceso de Tlatelolco, donde fueron asesinadas cientos de personas, entre ellas estudiantes, profesores y demás manifestantes, que solicitaban un cambio generacional con una postura política revolucionaria ante la ansiedad por las restricciones de libertad-.

En este sentido, la obra de Revueltas se inserta en el ámbito literario de la prisión para explorar los atributos aberrantes de nuestra realidad donde " $[. .$.$] la enajenación$ humana ha llegado a un extremo tan radical que lo humano verdadero sólo puede realizarse con la muerte" (Revueltas, Conversaciones 11). Asimismo, en el corpus literario de Revueltas es evidente el desarrollo de cierto tipo de dialéctica dirigida hacia la investigación fenomenológica de las relaciones humanas bajo una perspectiva sumamente negativa y deletérea, práctica que el mismo autor denomina a través de 
la emblemática expresión "lado moridor". ${ }^{1}$ El espacio carcelario, entonces, crea una microsociedad con reglas propias y se desarrolla paralelamente en otro espacio más amplio definido por un ordenamiento que, desde luego, lo comprende. Efectivamente, el análisis de un producto de nuestra sociedad, de la educación disciplinaria "necesaria" para que el modelo de vigilancia jerarquizado funcione, es una ventaja que permite reflexionar sobre la entidad creadora de tal sistema definiendo el grado de libertad en cada una de sus esferas de poder. En otras palabras, la cárcel proyecta la sociedad y viceversa. Es justamente el contexto carcelario que, entendido como la creación de un espacio/lugar otro, cercano al concepto de utopía social materializada, se extiende y se dilata hacia la heterotopía. Es decir, según la definición foucaultiana, se trata de un lugar que entretiene

[...] avec 1'espace réel de la société un rapport général d'analogie directe ou inversée. C'est la société elle-même perfectionnée $[\ldots]$ des lieux réels, des lieux effectifs $[\ldots]$ qui ont dessinés dans l'institution même de la société, et qui sont des sortes de contreemplacements [...] des sortes de lieux qui sont hors de tous les lieux, bien que pourtant ils soient effectivement localisables. (Dits et Ecrits 755-56)

Así, la cárcel se identificaría como una "heterotopía de desviación” ya que sus usuarios son personas que muestran hábitos que se alejan de las normas impuestas por el sistema del poder. De tal manera, esta institución no debería considerarse como una estructura que obedece a procedimientos disímiles a los de la sociedad de masas, sino como la realización de la racionalidad aplicada a través de la ley positiva hasta tal punto que, como nos explica Michael Hardt:

[...] When you get close to prison, however, you realize that it is not really a site of exclusion, separate from society, but rather a focal point, the site of highest concentration of a logic of power that is generally diffused throughout the world. Prison is our society in its most realized form [...]. (66)

Precisamente, Hardt ni siquiera ratifica una relación entre cárcel y sociedad, sino que yuxtapone los dos términos identificando la habilidad, por parte de nuestra lógica de poder, de generar sistemas utópicos tangibles, heterotopías. Además, el teórico estadounidense vincula las dinámicas cotidianas de su vida privada con las de la institución cerrada en sentido del vacío temporal que experimenta en sus actividades reiteradas, "My life too is structured through disciplinary regimes [...]-work, commute, tv, sleep-[...] I live in prison time in our free society, exiled from living [...]" (66-67).

Definición acuñada en el prólogo a la segunda edición de Los muros de agua (18). Para un estudio más detallado, recordamos el análisis de Evodio Escalante, José Revueltas: literatura del "lado moridor".

Revista Iberoamericana, Vol. LXXIX, Núms. 244-245, Julio-Diciembre 2013, 1017-1032 ISSN 0034-9631 (Impreso) ISSN 2154-4794 (Electrónico)
Ahora bien, si consideramos la óptica de los estudios que se acercaron a los textos narrativos de Revueltas, notamos que la mayoría de ellos vincula paulatinamente la vida personal del autor con la experiencia política y social de México de los sesenta. Es decir, tanto su experiencia como prisionero como el fuerte compromiso político y ético que siempre caracterizó su vida y su producción parecen recopilar el trasfondo dramático notificado en las páginas de sus mejores libros y, sobre todo, de El Apando. El digno esfuerzo de otorgar cierta integridad filosófico-política al pensamiento y a los escritos del autor mexicano ha promovido, en cierta medida, la creación de una línea crítica recurrente que, a veces, se limita a la formación de clichés y estereotipos ligados a lo biográfico que suelen encerrar el campo semántico de sus textos narrativos. En contraste con esta tendencia, en este ensayo propongo un acercamiento al texto de una de las voces más elocuentes de los sesenta latinoamericanos mediando la subestructura del discurso político contemporáneo al autor y proponiendo una apertura hacia una más atenta y profunda exploración de los fenómenos humanos que constituyen, modifican y subvierten la percepción común de la noción de subjetividad. Más específicamente, dentro del marco representativo de un género que puede identificarse como literatura carcelaria, donde el concepto inicial de heterotopía nos parece de fundamental importancia para contextualizar la retórica de Revueltas, el análisis de El Apando que propongo en este ensayo quiere indagar sobre los procesos que amplifican la relación entre la persona y la construcción de un contexto paralelo justificado por la falta de libertades y la imposición de normas, por el espacio carcelario. En este sentido, analizaré los procesos sociológicos que permiten cierto tipo de deshumanización -alejamiento de la sociedad, jerarquía de las relaciones y persistente control de las actividades-, cuestiones que presuponen una primera forma de segmentación de la sustancia interior del ser humano, y la creación de un orden que se aleja -o que posiblemente se acerca- de la naturaleza misma del hombre hacia un contexto dominado por los instintos. De tal manera, asistiremos a cambio repentino del sujeto -manipulado por estas privaciones- en objeto "reificado" por la institución carcelaria. Al mismo tiempo, trataré el discurso de la corporeidad, considerando la fragmentación anatómica de los personajes y la construcción de cierto tipo de animalidad mediante algunos comportamientos sintomáticos del encierro, que deterioran la unidad de la persona y que la acercan a un estadio primordial de barbarie. Mi objetivo es, en última instancia, demostrar que el así llamado "lado moridor" de la poética de Revueltas no solamente atañe a la responsabilidad de la denuncia de las dinámicas de poder en la sociedad por mano de la política, sino que también indaga en los procesos más hondos del ánimo humano ampliando el espectro ontológico de este lugar clausurado por medio de un procedimiento analítico. 
HACIA LA “DECONSTRUCCIÓN” DEL SUJETO

Laidentificación de una serie de desviaciones en la sociedad-desviación, desde luego, criminal pero pueden considerarse también como extravíos sociales las condiciones que implican un estatus "anormal" del sujeto como la enfermedad o la vejez- es un hecho imprescindible para el mantenimiento del orden en el modelo masivo de Occidente. Esto sucede porque la sociedad occidental no quiere y no puede procesar el lado incómodo y molesto de su alteridad que, paradójicamente, caracteriza la estructura del individuo y de la masa, en este caso, considerada como conjunto de individuos. De todas formas, si recordamos la definición de heterotopía de Foucault, destacamos el concepto de "contralugar", o de "lugar otro", para subrayar el prejuicio social hacia un lugar que no sirve para resolver el problema de la criminalidad sino que, al contrario, construye y forma sujetos "otros" o, mejor dicho, la otredad de la sociedad. El método escogido por nuestra sociedad "capitalista-productiva"" para exorcizar una de sus varias contradicciones se identifica con el alejamiento de los sujetos anómalos mediante la construcción de una ideología que los define éticamente incurables e incomprensibles. En este sentido, "la prison fabrique des délinquants [...] il a fallu absolument constituer le peuple comme un sujet moral, donc le séparer de la délinquance, donc séparer nettement le groupe des délinquants, les montrer comme dangereux [...]" (Foucault, "Entretien" 28-29) para la estructuración misma de la moralidad social.

La formación del Otro se funda en la "deconstrucción" parcial del concepto del "yo" en un contexto clausurado como el de la cárcel. Recordemos, entonces, que en la misma década de la publicación de El Apando, aparece un importante estudio sociológico sobre la condición de los internos dentro de las "instituciones totales", como los hospitales psiquiátricos, las cárceles y los campos de concentración. Según las observaciones de Erving Goffman en Asylums (1961), para que las políticas carcelarias cumplan con la reeducación de los reclusos, es necesario, entre otras cosas, que la institución debilite una serie de facultades del sujeto detenido. Así que la manipulación de la subjetividad se desarrolla, en primer lugar, a través de la condición misma del preso al estar alejado de la sociedad, fuera del mundo exterior. De tal manera, el primer paso hacia la mortificación del "yo" es justamente la modificación de las relaciones sociales a través de la construcción de una jerarquía que altera la relación entre carcelero y detenido, pero también entre detenido y familiares, y entre los detenidos mismos. Consecuentemente, la

\footnotetext{
Franco y Franca Basaglia en el epílogo de Asylums de Erving Goffman (401-415) afirman que [... "nella società capitalistico-produttivistica la norma è la salute, la giovinezza, la produzione. La malattia, la vecchiaia, l'infortunio sono accidenti all'interno di una realtà che non vuole e non puo premunirsi e preoccuparsi delle proprie contraddizioni [...] Si salva ciò che può essere facilmente recuperato; il resto viene negato attraverso l'ideologia dell'incurabilità, dell'incomprensibilità, della natura umana, su cui si
} costruisce il castello del pregiudizio [...]" (410-411).

17. Revista Iberoamericana, Vol. LXXIX, Núms. 244-245, Julio-Diciembre 2013, 1017-1032 \begin{tabular}{llll} 
Revista & Iberoamericana, Vol. LXXIX, Nums. & 244-245, & Julio-Diciembre \\
\hline ISSN 0034-9631 (Impreso) & ISSN 2154-4794 (Electrónico)
\end{tabular} pérdida de todos los bienes materiales mutila la identidad del sujeto que se reduce a una colección de "fetiches", pertenecientes o no al mundo exterior, y en relación a la cual el recluso se construye una nueva y propia identidad. Finalmente, el espacio de acción del internado sufre una considerable reducción, no sólo con respecto a la dimensión del lugar claustrofóbico donde vive, sino también a causa de la constante vigilancia de los guardias. Esta serie de privaciones, que por supuesto no pretende ser un registro exhaustivo de todas las aberraciones de la identidad, juega un papel de fundamental importancia para la creación de un "sujeto-objeto" fácil de manipular y domesticar en la obra de Revueltas. Asimismo, para identificar estos procedimientos que demarcan el encierro y la claustrofobia narrativa, empiezo el análisis a través de un enfoque estilístico de El Apando o, más bien, considerando el método estructural y retórico del texto.

Es preciso subrayar el hecho de que el relato se desarrolla a través de un párrafo único y la falta de apartados hace que el discurso sea indivisible de manera que se percibe como una única argumentación, una especie de lugar cerrado. ${ }^{3}$ A menudo, las frases siguen un esquema hipotáctico, de marcada subordinación sintáctica que les confiere una importante extensión textual, no permitiéndole al lector tomar aliento y pausar su actividad. Así pues, el ritmo de la narración está afectado por este mismo recurso que casi solicita una lectura en voz alta para expresar la complejidad del sentido afanoso de la ejecución. Propiamente, se trata de un afán espacial que resalta la condición de los presos pero, también, de una ansiedad a nivel temporal, de la posibilidad de describir una estadía entera en la cárcel tomando como ejemplo un día cualquiera, ya que la redundancia de las actividades diarias homologa la experiencia carcelaria. En este sentido, el espacio de la cárcel se hace simulacro de un hic et nunc existencial donde el tiempo está cristalizado y donde las actividades humanas pierden sus valores justamente a causa de la reiteración de los gestos. Notamos, entonces, que El Apando es la argumentación de un hecho particular dentro del contexto cerrado y homogéneo -la huelga de las mujeres, una protesta que reivindica el estado aberrante de los reclusos en el calabozo de máxima vigilancia, el apando, y que es utilizada como escamoteo para la introducción de droga en la institución-y, por lo tanto, la narración es una constante divagación basada en la única fuente posible de evasión para los detenidos, los recuerdos de acontecimientos previos al momento de la argumentación.

Sin embargo, en una lectura más profunda de la novela, podemos aislar los pasajes que se refieren únicamente a la acción acontecida en la cárcel con lo que nos damos cuenta de que lo único que pasa antes de la huelga es el cambio de "vigilancia" de Polonio

Revueltas, en un diálogo sobre El Apando en la Universidad Veracruzana en 1975, contestando a una pregunta sobre la sensación de encerramiento de su recurso retórico, afirma que: "No fue una idea preconcebida, sino una necesidad del material. El material no permitía la respiración, la tensión era a ta extremo vigorosa que es imposible poner un punto y aparte [...] El texto debe representar un hermetismo, es un espacio cerrado" (Revueltas, Conversaciones 39).

Revista Iberoamericana, Vol. LXXIX, Núms. 244-245, Julio-Diciembre 2013, 1017-1032 ISSN 0034-9631 (Impreso) ISSN 2154-4794 (Electrónico) 
y Albino en el calabozo, intercalándose con la continua insistencia de El Carajo en disfrutar esta oportunidad que se le ha negado. Es decir, el texto dedica más de un tercio de su extensión al desarrollo de su estatismo constitutivo aunque la singular dinámica de la huelga crea el hecho que rompe con la normalidad de la cárcel. Esto quiere decir también que los "fotogramas" del recuerdo intervienen en la compulsión espectral de la argumentación para el planteamiento de una protohistoria de los personajes, inteligible en función del contexto carcelario. De esta forma, la simultaneidad de las dos historias amplifica este sentido de inefable confinamiento espacial y temporal y que confluyen juntas en un párrafo del tamaño de poco menos de cuarenta y cinco páginas, El Apando.

Anteriormente, he mencionado, utilizando un eufemismo, la capacidad de los presos para "vigilar" la crujía de la cárcel. Esto surge, desde un primer momento, como inversión de los papeles entre reclusos y carceleros por la posibilidad -en este caso de Polonio a través de sus contorsiones para lograr una postura adecuada que le permita sacar la cabeza fuera de la celda- de dominar los movimientos de los vigilantes "desde lo alto con el ojo derecho clavado hacia la nariz en tajante línea oblicua"(12), planteando así la idea de que los centinelas pueden ser controlados por todos los encarcelados. Efectivamente, aunque ellos -los vigilantes- "se sabían hechos para vigilar, espiar y mirar en su derredor, con el fin de que nadie pudiera salir de sus manos, ni de aquella ciudad y aquellas calles con rejas", al mismo tiempo, estaban "cubiertos de ojos de la cabeza a los pies, una malla de ojos por todo el cuerpo, un río de pupilas recorriéndoles cada parte, la nuca, el cuello, los brazos, el tórax" (13-14). En este sentido, el modelo de vigilancia por excelencia, representado por el Panóptico y por el potencial de una mirada total en el interior de la geometría del edificio, parece dirigido, esta vez, hacia los detentores del poder para evidenciar cómo la institución incluye en su actividad un sentido de encerramiento igualitario. Sin embargo, en este caso, la situación que homologa a las personas en la Cárcel Preventiva no es tanto el punto de vista de quien mira, sino la percepción de un lugar aséptico, atemporal y de recambio continuo. Solamente hace falta mencionar una breve descripción bastante detallada del interior de la cárcel para percibir que se trata de un lugar totalizador que nivela los rasgos connotativos de todos los que operan en su interior:

Cuando Meche trasponía la primera reja hacia el patio que comunicaba con las diferentes crujías, dispuestas radialmente en torno de un corredor o redondel donde se erguía la torre de vigilancia-un elevado polígono de hierro, construido para dominar desde la altura cada uno de los ángulos de la prisión entera [...]. (31)

Así, notamos un cambio de perspectiva que se relaciona con la sinonimia entre la cárcel y la sociedad porque:

Revista Iberoamericana, Vol. LXXIX, Núms. 244-245, Julio-Diciembre 2013, 1017-1032 ISSN 0034-9631 (Impreso) ISSN 2154-4794 (Electrónico)
Aunque el "cajón" formara parte de la Crujía, separado de ésta únicamente por las mismas rejas que servían [...] de límite, la presencia de los celadores de guardia, encerrados ah dentro, le daba el aspecto de una cárcel aparte, una cárcel para carceleros, una cárcel dentro de la cárcel. (40)

El reconocimiento de una autoridad de vigilancia perpetua y subrepticia -ya que solamente un encargado puede controlar las condiciones de todas las celdas sin ser visto- concientiza sobre el derrumbamiento de la propiedad privada, en el sentido de privación de la libertad para actuar con espontaneidad. Así pues, el modelo panóptico opera de manera automática a través de una anatomía de poder expandida y sin violencia, justamente como la estabilidad planteada por las reglas del decoro social que son asimiladas pasiva e imperceptiblemente por los usuarios de cualquier espacio social. Aquí, entonces, el mecanismo de objetivación del sujeto encuentra su punto tangencial con la sociedad donde se exaspera la necesidad de inventariar las identidades por medio de códigos seriales compuestos por números que, como ocurre analógicamente en el texto de Revueltas, procede de la "[...] gigantesca derrota de la libertad a manos de la geometría" (55), esto es, de una superestructura originada y programada por la racionalidad del hombre como método de inclusión en la racionalidad misma.

Con respecto a la consecuencia del ingreso en la institución carcelaria, El Apando sugiere una lectura específica de las modificaciones de las relaciones sociales como causa del despojamiento de la identidad del sujeto encarcelado. Dicho fenómeno remite a una sociedad primordial sin construcciones complejas o no propiamente definidas. El proceso que lleva a este tipo de deposición compositiva del desarrollo del hombre, que más bien podríamos entender como un regreso evolutivo, se configura a través de una terminología específica que pertenece al ámbito animal. A pesar de que la identificación de los guardias está metaforizada, ya desde el comienzo, mediante semejanzas animalizadas, podemos notar un cambio gradual de las actitudes de los visitantes de los presos en distintas ocasiones. ${ }^{4}$ En este sentido, "[c]uando alguna señora de clase alta llegaba a pisar estos lugares, las primeras veces, su preocupación única, obsesiva, manifiesta [...] era la de establecer un límite social preciso entre su preso [...] y los presos de las demás personas" (43), reclamando la injusticia de las acusaciones infames a cargo del propio visitado desde lo alto de su opulencia. Pero, después de un tiempo, "la señora de alcurnia iba modificando poco a poco su actitud y haciendo concesiones a la realidad $[\ldots]$ hasta que por fin entraba a la categoría de las visitantes normales y terminaba por

Es interesante notar, a través de las palabras del autor, cómo un hecho real se traspone y adquiere sentido dentro del texto al identificar a los carceleros con los monos: "[...] los monos son el Estado. Pero esta designación no es una implicación zoológica de mi parte, dado que a los vigilantes les dicen 'monos', y ellos se llaman a sí mismos, 'monos'. 'Soy mono en Lecumberri', contestan si les preguntan en que trabajan [...]” (Revueltas, Conversaciones 40).

Revista Iberoamericana, Vol. LXXIX, Núms. 244-245, Julio-Diciembre 2013, 1017-1032 ISSN 0034-9631 (Impreso) ISSN 2154-4794 (Electrónico) 
pasar inadvertida" (43). Otra vez, la configuración de los esquemas sociales ingresa en la institución en toda su integridad para después convertirse en una toma de conciencia con respecto a la generación de un orden nuevo, censurado de sus adquisiciones sucedáneas y complementares. Aún más relevante es la descripción de la nueva disposición social que se constituye en el interior de la cárcel con lo que el cuadro narrativo ofrecido por El Apando resulta ser bastante explícito:

Durante la visita de los familiares, el patio de la Crujía se transformaba en un estrafalario campamento, con las cobijas extendidas en el suelo y otras, sujetas a los muros entre las puertas de cada celda, a guisa de techumbre, donde cada clan se reunía, hombro con hombro, mujeres, niños, reclusos, en una especie de agregación primitiva y desamparada [...]. (48)

Como se puede notar en este fragmento, la desestabilización de las relaciones interpersonales, como efecto de la clausura carcelaria, implica un moldeamiento social que remite hasta al hombre primitivo y sus recursos.

En síntesis, la modificación del contexto espacial a través de la aplicación de un método general de vigilancia como el panóptico, logra mistificar la subjetividad mediante la enajenación de las prácticas cotidianas. La remoción repentina de una serie de facultades propias de la persona permite delimitar el concepto del "yo". En este sentido, "Il più semplice giudizio sociologico dell'individuo e del suo sé, è che egli sia per sé ciò che la sua condizione nell'organizzazione definisce que egli sia" (Goffman 335-336). Paralelamente y paradójicamente, esto implica que la pertenencia total a cualquier tipo de entidad social perjudicaría de igual forma la subjetividad.

UNA SEMASIOLOGÍA SENSORIAL DE LOS FRAGMENTOS ANATÓMICOS: EL ANIMAL

Una de las observaciones formuladas por Foucault con respecto al origen del modelo del Panopticon de Bentham se refiere al arquetipo de encierro construido por Le Vaux en la ciudad francesa de Versailles para el cuidado de los animales del circo, la managerie. La principal modificación aportada por el jurista británico fue, entonces, la de reemplazar los animales por los hombres. Empiezo con esta previa consideración para reflexionar sobre un concepto implacable en El Apando -el de la animalidad y las referencias zoológicas-y para delinear el archivo que Revueltas maneja para demostrar que este remplazo de Bentham podría más bien considerarse una conversión.

El enfoque narrativo múltiple de la novela permite una percepción sensorial original y profunda. Se trata de una narración heterodiegética pero de una entidad que tiene cierto tipo de omnisciencia con respecto a los recuerdos y a las acciones en las que no participa directamente. Además, su capacidad de observación minuciosa desemboca en una penetración del detalle que sugiere el desplazamiento en el campo de las imágenes

Revista Iberoamericana, Vol. LXXIX, Núms. 244-245, Julio-Diciembre 2013, 1017-1032 ISSN 0034-9631 (Impreso) ISSN 2154-4794 (Electrónico) potenciando el panorama alegórico de las oraciones. Como ya he referido, la estructura carcelaria tiene la potencialidad de homologar la esencia del sujeto-tanto de los detenidos como de los carceleros- $y$, en este sentido, el narrador utiliza la función del panóptico al revés para demostrarlo. Además, ya en la apertura de la novela, notamos una atención léxica en referencia a algunos términos particulares, como "escala zoológica", "enjaulados", "amaestramiento", "natural", "sin memoria" (11), que incitan la referencia al mundo animal. Sin embargo, el sistema de la cárcel se basa en una escala jerarquizada que se plantea alrededor del mayor o menor espacio de acción -entre ellos, recordamos a los carceleros, presos comunes, presos políticos y apandados-. Es justamente uno de los términos mencionados que llama particularmente la atención porque refleja otro tipo de jerarquía que reconoce un poder más alto capaz de "amaestrar" a los animales. Definir a los celadores como seres antropomorfos que "[s]e sabían hechos para vigilar" (13), implica, a través de la utilización de la forma pasiva, una deducción muy elemental que se refiere al hecho de que éstos serían animales desbravados, que recibieron cierto tipo de domesticación, mientras que los presos estarían todavía en una condición salvaje, en busca de civilización y, por este motivo, están encerrados. ${ }^{5}$

La fragmentación del cuerpo es otro elemento de El Apando que causa, paralelamente a la clausura y a la reducción de las libertades personales, la segmentación del "yo" a nivel figurativo y, por este motivo, el proceso provoca cierta forma de hostilidad hacia y entre los personajes. De todas formas, el proceso de fraccionamiento del sujeto que permite la objetivación del criminal se inserta en el texto a través de las descripciones de partes del cuerpo, acción justamente cometida ante la mirada del narrador. A pesar del hándicap que impide a El Carajo cumplir con la tarea de "vigilancia" desde el interior del espacio limitado del calabozo, Albino y Polonio son los únicos personajes que pueden inspeccionar el espacio de abajo y sobre los cuales recae dicha transformación. Así, el primer fragmento anatómico que se refiere a los presos del apando es una alegoría casi pictórica de la cabeza "guillotinada" de Polonio/Bautista "sobre la charola de Salomé, fuera del postigo, la cabeza parlante de las ferias, desprendida del tronco" (12) para después pasar a la cabeza "decapitada" de Albino/Holofernes, representada en términos aun más grotescos que la anterior, "igual que el cuerpo de un pez monstruoso, con cabeza humana [...] con su único ojo que giraba en redondo, desesperado, en la misma forma en que lo hacen las reses cuando se las derriba en tierra y saben que van a morir" (45-46). Notamos aquí otro tipo de espacialidad que antes había sido omitido. Es un espacio que podríamos definir "hipoterotópico" porque se establece en un lugar descontextualizado del cuerpo, no bien definido y ambivalente. En este caso, el cuerpo está dentro de la celda mientras que la cabeza está afuera, es decir, no podemos hablar de un espacio liminar

De alguna manera, esto confirma la posición de poder que se expresa a través de la metáfora empleada por Revueltas al identificar los monos con el Estado (Revueltas, Conversaciones 40) proponiendo, otra vez, la analogía entre cárcel y sociedad.

Revista Iberoamericana, Vol. LXXIX, Núms. 244-245, Julio-Diciembre 2013, 1017-1032 ISSN 0034-9631 (Impreso) ISSN 2154-4794 (Electrónico) 
porque el límite de la celda no permite dicha colocación. En este sentido, el término "hipoterotopía" definiría aquel espacio, tangible dentro del contexto carcelario, que, a diferencia de la heterotopía, no permite ejecutar una acción en su integridad a causa de una doble espacialidad estática -adentro y afuera- que asimismo comporta una doble temporalidad -el tiempo interno y el tiempo externo-. Además, la "hipoterotopía" se distinguiría de la heterotopía porque no está conectada con los demás espacios que la rodean sino solamente con un límite de espacios. Se trataría de una espacialidad cerrada dentro de otro lugar cerrado y por esto su existencia y legitimación se halla sólo y exclusivamente en relación con la heterotopía. En el caso de El Apando, el efecto de esta espacialidad se podría relacionar con la parcialidad de la mirada de los presos hacia el sector de la Crujía que logran mirar. ${ }^{6}$

Sin embargo, antes de empezar el análisis sobre El Carajo, personaje que encarna, junto a su madre, la mayoría de las referencias deshumanizantes que se presentan en el texto, quiero detenerme en la atribución de su nombre. Indudablemente, El Carajo es un seudónimo que remite a sus disfunciones físicas "pues por eso lo apodaban El Carajo, ya que valía un reverendo carajo para todo, no servía para un carajo, con su ojo tuerto, la pierna tullida y los temblores con que se arrastraba de aquí para allá, sin dignidad [...]" (15). En este sentido, es fundamental reconocer el hecho de que su nombre le ha sido aplicado por personas ajenas -Albino, Polonio, los detenidos en general o el narrador-. Es decir, la acción de nombrar a alguien denota cierto tipo de superioridad por parte del que nombra y puede ser interpretado como la identificación del Otro, del chivo expiatorio para los demás. La fórmula parece análoga a la que sugiere Jacques Derrida en sus consideraciones sobre la construcción del "yo" a través de la animalidad utilizando la metáfora del gato mirando al hombre desnudo y que éste tiene que identificar al gato como animal para poder, después, autodefinirse como hombre. Es el mecanismo que proviene de la hegemonía del lenguaje -o por lo menos de nuestro código lingüístico que solamente nosotros, los hombres, podemos entender- para distinguirnos de las demás especies vivientes que no pueden comunicarse con el ser humano.

Les hommes seraient d'abord ces vivants qui se sont donné le mot pour parler d'une seule voix de l'animal et pour désigner en lui celui qui, seul, serait resté sans réponse, sans mot pour répondre [...] il se ressemblerait plutôt dans ce mot, l'animal, que les hommes se sont donné, comme à l'origine de l'humanité, et se sont donné afin de

\footnotetext{
El concepto de "hipoterotopía" podría considerarse como variante de la "utopía del espejo" presentada por Foucault en el texto Des espaces autres si no fuera por el énfasis constitutivo del análisis del fenómeno. En este en del reflejado - el espacio es un no-lugar sin la presencia de un actor que lo produzca- desatendiendo, al contrario, la libertad de acción que en la "hipoterotopía" se proyectaría de manera drásticamente mutilada.
}

17. Revista Iberoamericana, Vol. LXXIX, Núms. 244-245, Julio-Diciembre 2013, 1017-1032 ISSN 0034-9631 (Impreso) $\quad$ ISSN 2154-4794 (Electrónico) s'identifier, pour se reconnaître, en vue d'être ce qu'ils se disent, des hommes, capables de répondre et répondant au nom d'hommes. (Derrida 54)

Así pues, se justifican las acciones feroces que los dos camaradas de reclusión le infligen al animal/otro/El Carajo para defender su estatus de Hombre. En este sentido, a través de la privación del acceso directo al lenguaje, “[...] on perd le pouvoir de nommer, de se nommer, voire de répondre de son nom" (Derrida 38) hasta el punto en que, como en el caso de la naturaleza y de los animales, "[...] ce qui lui interdit le mot, ce n'est pas un mutisme et l'expérience d'un impouvoir, un ne-point-nommer, c'est d'abord de recevoir le nom" (Derrida 39). Siempre considerando la esfera del lenguaje, recordemos que El Carajo no solamente recibe su apodo sino también se acerca a la palabra únicamente en dos ocasiones por un periodo de tiempo limitado mientras que, durante todo el resto de la argumentación, su manera de expresarse se localiza en la emisión de aullidos, gritos, llantos, gemidos o, de todas formas, sonidos desarticulados. ${ }^{7}$

La fractura sintomática experimentada por el personaje a través de la falta del habla provoca, en cierta medida, la concepción de una subjetividad paralela, despojada de todas sus construcciones sociales. Justamente por este motivo, el proceso de objetivación del sujeto parece acercarse a una fase primordial del hombre. En este sentido, El Carajo vuelve a ser una entidad con propiedades animales cuando se le compara con un chivo (41) o también cuando actúa como "una tarántula maligna, con la misma sensación que invade los sentidos cuando la araña, bajo el efecto de un ácido, se encrespa, se encoge sobre sí misma [...] y sin embargo no muere, no muere, y uno quisiera aplastarla pero [...] no se atreve" (33). Los movimientos de El Carajo son torpes y descompuestos también a causa del uso de drogas. Una de las escenas donde se percibe dicha dificultad de movimiento se halla, por ejemplo, en el momento en que Polonio lo ve por primera vez en el jardín de la enfermería, lugar que El Carajo frecuenta periódicamente a causa de sus seudosuicidios y para sanar el efecto de la abstinencia. En esta circunstancia, El Carajo está agitándose extrañamente en una “danza semi-ortopédica”, flexionando

la pierna sana, la tullida en posición de firmes, las manos en la cintura y la punta de los pies hacia afuera $[\ldots]$ para intentar $[\ldots]$ unos pequeños saltitos adelante, con lo

La primera vez, El Carajo expresa el deseo, desde luego negado, de poder ver a su madre desde la minúscula abertura de la celda mientras que ella le traía la droga según los planes. La última vez que

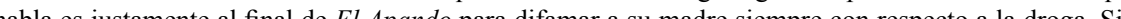
habla es justa enbargo, en ambos casos, las palabras no tienen valor conuncativo en el senido del intercambio un mensaje porque, en el primer caso, el narrador interviene intercalando, hablaba como un niño, $\mathrm{m}$ mamá, cuando debía decir mi puta madre" (24), mientras que en la segunda ocasión "fuera del oficial nadie lo había escuchado. [Éste le] sonrió con una mueca triste" (56), secundándolo en su desesperación existencial.

Revista Iberoamericana, Vol. LXXIX, Núms. 244-245, Julio-Diciembre 2013, 1017-1032 ISSN 0034-9631 (Impreso) ISSN 2154-4794 (Electrónico) 
que perdía el equilibrio e iba a dar al suelo, de donde no se levantaba sino después de grandes trabajos, revolviéndose a furiosas patadas que lo hacían girar en círculo [...].(19)

El hándicap del hombre, junto al estado etéreo causado por los estupefacientes originan la misma ineptitud de la tortuga que fatalmente se encuentra bocarriba. E instinto de retomar la postura humana lo agita frenéticamente hasta convertirlo en un caricaturesco, y al mismo tiempo trágico, animal de circo. El expediente del objeto inútil, o del animal, permite a los demás compañeros relacionarse con él de manera brutal y salvaje. La construcción de estas condiciones reduce el personaje a mero objeto hasta el punto en que sus compañeros de celda lo ven "como un saco inerte en el rincón [de la celda]" (33). Es decir, en este caso, el sistema carcelario implementa los mismos procesos naturales con respecto a la supervivencia del más fuerte, lo cual implica que todos los reclusos actúan dentro de esa misma lógica salvaje.

De manera análoga, cabe subrayar que la referencia a la droga no es casual. Este recurso parece ser laúnica manera de restablecer una condición perceptiva de normalidad del personaje con su entorno. El cuerpo envilecido de El Carajo es un objeto que:

$[\ldots]$ parecía no pertenecerle, pero que disfrutaba $[\ldots]$ con el más apremiante y ansioso de los fervores, cuando lograba poseerlo, meterse en él, acostarse en su abismo, al fondo, inundado de la felicidad viscosa y tibia, meterse dentro de su propia caja corporal, con la droga como un ángel blanco y sin rostro que lo conduciría de la mano a través de los ríos de la sangre, igual que si recorriera un largo palacio sin habitaciones y sin ecos. (15-16)

Su cuerpo es un medio para el deleite físico y anímico puesto que la droga representaría el pegamento por medio del cual todos los fragmentos anatómicos generados, sobre todo, por la narración y perpetuados por sus compañeros volverían a encontrarse nuevamente en la misma "caja corporal". Sin embargo, con estas palabras, no queremos victimizar al personaje de El Carajo justificándolo como chivo expiatorio de la sociedad carcelaria pero sí enfatizar el hecho de que su representación es el producto que surge de ella. La droga, entonces, desempeña un papel central para el rescate de la única propiedad, el cuerpo, que los mecanismos de la institución se ocuparon de desmantelar previamente y que todavía le parece extraña, no familiar. Al mismo tiempo, su pérdida simbólica dentro de este "palacio humano" lo encamina hacia la felicidad -aunque viscosa y tibia- "y cómo ya no le importaba nada de nada sino nada más el pequeño y efímero goce [...] para obtener ese descanso, que era lo único que él amaba en la vida [...] esa libertad en que naufragaba, a cada nuevo suplicio, más feliz" (34). No obstante, el cuerpo de El Carajo es un cuerpo deteriorado de "un anti-Dios maltrecho, carcomido [afectado por] broncas convulsiones de una tos frenética, galopante" hasta el punto que "Parecía un endemoniado con el ojo de buitre colérico al que asomaba la asfixia [...] Era un verdadero estorbo este tullido" (36-37). Si bien la enajenación de este personaje procura aliviarse a través de la droga, notamos en su figura una tendencia iconográfica hacia la enfermedad, pero no una enfermedad infecciosa cualquiera, sino algo que provoca repugnancia como, por ejemplo, cuando

[...] a un lado de la nuca, un poco atrás y debajo de la oreja, Polonio sentía sobre la piel el beso húmedo de la llaga purulenta en que se había convertido una de las heridas no cicatrizadas de $E l$ Carajo, los labios de un beso de ostra que lo mojaba con algo semejante a un hilito de saliva que le corría por el cuello hacia la espalda [...]. (23)

Mientras que en otra ocasión, "esa pequeña costra húmeda, no endurecía todavía, el pus, el pus de la herida abierta de El Carajo que éste le dejara adherido a la mano durante el forcejeo y que Albino estuvo a punto de untarse en los labios" (37) nos remite a la condición de los enfermos de peste. Las reacciones de los apandados se cargan, consecuentemente, de odio brutal hasta el punto que, en ellos, aumenta el deseo de aliviarle de sus aflicciones quitándole la vida.

Efectivamente, lo que surge a través de estas circunstancias es una reacción de rechazo total causada por la náusea hacia la figura de El Carajo. La evolución analítica que proponemos se acerca al concepto de lo "abyecto" propuesto por Julia Kristeva en sus ensayos sobre el horror. En este sentido, Kristeva postula que "the abject has only one quality of the object -that of being opposed to $I$ " (1). De la misma manera, Revueltas deshumaniza a su personaje y lo vuelve en el objeto/animal necesario a fin de que pueda desarrollarse un sentido de alteridad, la misma que permite identificar a los demás personajes como sujetos. Esto es, el sujeto está forjado por la experiencia y, al mismo tiempo, se construye a través de diferentes objetos. Los objetos materiales contraseñan la exterioridad de un individuo y su clase social de pertenencia mientras que los objetos intangibles -si con este término designamos los conceptos, los principios y las ideas- definen la personalidad y la actitud hacia el mundo. Así, ambos constituyen la identidad del sujeto per se. La fragmentación operada con respecto a la subjetividad de El Carajo -que ni siquiera el "pequeño y efímero goce" de la droga puede redimirmuestra su encadenamiento dentro del contexto que sirve a los demás para crearse como sujetos. Refiriéndose al discurso sicoanalítico del "rechazo original" del lenguaje simbólico materno, Kristeva delínea lo abyecto como una representación que sufre su represión solamente a posteriori. Se trataría, entonces, de una represión que afecta la esfera corporal cuyos síntomas son la repugnancia, la aversión y, en fin, la abyección (11). Sin embargo,

The abject might then appear as the most fragile $[. .$.$] the most archaic [\ldots]$ sublimation of an "object" still inseparable from drives. The abject is that pseudo-object that is made before but appears only within the gaps of secondary repression. The abject would thus be the "object" of primal repression. (12)

Revista Iberoamericana, Vol. LXXIX, Núms. 244-245, Julio-Diciembre 2013, 1017-1032 ISSN 0034-9631 (Impreso) Vol. LXXIX, Núms. 244-245, Julio-Diciembre 2013, $1017-1032$
ISSN 2154-4794 (Electrónico)
Revista Iberoamericana, Vol. LXXIX, Núms. 244-245, Julio-Diciembre 2013, 1017-1032 ISSN 0034-9631 (Impreso) ISSN 2154-4794 (Electrónico) 
En el caso de El Apando, dicha represión primitiva se hallaría en la concientización evolutiva que del animal llega hasta al hombre. Así que, cuando uno se enfrenta, por ejemplo, a un sentimiento de vergüenza o de pudor, como ocurre en el caso del gato ya mencionado por Derrida, y no sólo percibe estos sentimientos, sino que se da cuenta de tener vergüenza de su vergüenza (Derrida 29-30), reconoce a la vez su construcción perceptiva y su procedencia generativa. Al entrar en contacto con " $m a$ passion de l'animal" (29) la construcción mental planteada por el contexto cultural "remove it from the threatening world of animals or animalism" (Kristeva 13).

De tal manera, Kristeva reconduce esta represión primordial a la relación de la madre con el niño, ingresando éste en la esfera comunicativa del orden semiótico del padre. En el caso de El Carajo, parece que dicho alejamiento no pudo verificarse porque, metafóricamente, El Carajo aún no ha nacido. Efectivamente, si se considera la droga como el líquido amniótico que permite mantener en vida al feto, el papel de la madre de El Carajo sería el de subsidiar la constante presencia de este fluido. En ella, que antes le ofrece dinero para que él pueda mantenerse en vida y después procura entregarle la droga personalmente, reside la causa de la abyección. Aquí también resulta muy significativo que ella se encarga de llevarle "allí dentro el paquetito de droga [...] el paquetito para alimentarle el vicio a su hijo, como antes en el vientre, también dentro de ella, lo había nutrido de vida, del horrible vicio de vivir [...]" (23). Además, la imagen nauseabunda del embarazo desplazado en el "vientre lleno de lombrices" de la madre identificaría justamente el lugar donde el hijo se cría, "sin querer salirse de claustro materno, metido en el saco placentario, en la celda [...]" (20). Así que, el hecho de que la madre no logra entregarle el tapón vaginal con la droga, con su alimento, afecta el curso de la gestación acelerando el parto que se localizaría en el momento en que los carceleros lo sacan del apando, de la matriz oscura y protectora. El momento de la "abyección", entonces, reside en aquella acusación que El Carajo le infiere a su madre, segunda y última vez que el protagonista habla, al decir "“Ella [...] ella es la que trái la droga dentro, metida entre las verijas. Mándela a esculcar pa que lo vea"” (55-56). El rechazo separa, supuestamente, al hijo de la madre, el objeto del sujeto recién identificado a través de la alteridad que antes no lograba reconocer porque estaba estrictamente relacionada a la necesidad primaria de la alimentación. ${ }^{8}$ El surgimiento de cierto tipo de repulsión se basa, principalmente, en la percepción compositiva de sujeto fragmentado y privado de ciertas características, por así decirlo, humanas. Su objetivación o, como sugiere nuestro análisis, su animalización hace que el confín entre estas dos esferas no sea tan concreto y, por eso, pasible de una constante ambivalencia

\footnotetext{
En este sentido, recordemos también que Kristeva relaciona la existencia de lo abyecto con el concepto de "juouissance" que, desde luego, puede referirse al goce que provoca el consumo de drogas. El Carajo disfruta de la sustancia "gozando hasta lo indecible cada pedazo de vida que se le caía" (23), hasta que el deleite deteriora el cuerpo y lo hace introducirse en el orden de la peor bajeza humana.

17. Revista Iberoamericana, Vol. LXXIX, Núms. 244-245, Julio-Diciembre 2013, 1017-1032 ISSN 0034-9631 (Impreso) ISSN 2154-4794 (Electrónico)
}

interpretativa. Al mismo tiempo, lo abyecto se acercaría a lo animal en tanto en cuanto el objeto se aleja del hombre porque la fractura de la integridad que compone al "yo" causa un sentido de perdición y enajenación.

\section{CONCLUSIONES}

El espacio carcelario que Revueltas transmite como experiencia vívida y hallada en primera persona es la expresión sintomática del contexto social en que la obra se produce, esto es, cierto tipo de tensiones sociales relacionadas con los órganos políticos y la clase del poder que produjeron el movimiento estudiantil en México de 1968. En este sentido, El Apando se inserta en la discusión temática de una concreta enajenación y represión social propia de la literatura carcelaria y logra expresar, a través de un lenguaje violento e impulsivo, la exhortación hacia una apertura al diálogo de la sociedad con el poder. El desarrollo de una escritura contenida en un solo párrafo, metáfora del espacio cerrado de la celda, alude a la constricción que tanto los personajes como la sociedad tienen que obedecer. Al mismo tiempo, la galvanización del lenguaje, como producto de un regreso a los instintos primordiales del hombre, comprueba el resultado de la deshumanización del sujeto, incapaz de expresarse sino de manera angustiosa y afanosa, hecho que se plantea, en este caso, a través de la operación represiva por parte de la institución. El poder habla y actúa por medio de su hija, la institución, para homologar la sociedad, y así, en este orden, enajenar, fragmentar, objetivizar y animalizar sus componentes, a fin de que pueda crear una masa única y homogénea que responda pasivamente a sus intervenciones. La animalidad es una condición humana así como lo es la razón. La sociedad moderna no advierte, o incluso no reconoce, tal estructura así que hace todo lo que le compete para implementar la razón sobre algo que no la tiene por ser animal. En definitiva, esto es lo que no admite, percatarse del ser irracional que la compone. Al no poder controlar esta parte de sí, delega a otros lugares que resuelvan el problema. Justamente ahí, en el apando, se puede notar que los métodos para racionalizar no son racionales. De este modo, Revueltas proyecta hacia el futuro el escepticismo de su propio presente aunque sugiere la posibilidad de un discurso político para la recuperación de todos los fragmentos que la clase dirigente suprimió de la conciencia -ambivalenteque componía esa sociedad. 


\section{OBRAS CITADAS}

Derrida, Jacques. L'animal que donc je suis. Paris: Galilée, 2006.

Escalante, Evodio. José Revueltas: una literatura del "lado moridor”. México: Consejo Nacional para la Cultura y las Artes, 2006.

Foucault, Michel. Dits et écris, 1954-1988. Paris: Gallimard, 1994. Vol. 4.

"Entretien sur la prison: le livree et sa méthode". Magazine Littéraire 101 (1975): 27-33.

Goffman, Erving. Asylums. Le istituzioni totali: i meccanismi dell'esclusione e della violenza. Torino: Einaudi, 2001.

Hardt, Michael. "Prison Time." Yale French Studies 91 (1997): 64-79.

Kristeva, Julia. Powers of Horror: An Essay on Abjection. Leon S. Roudiez, trad. Nueva York: Columbia UP, 1982.

Revueltas, José. Antología personal. México: Fondo de Cultura Enonómica, 1975. Conversaciones con JoséRevueltas. Jalapa: Centro de Investigaciones LingüísticoLiterarias, Universidad Veracruzana, 1977. El Apando. México: Ediciones Era, 2005. 